\title{
Pannexin-1 is involved in neuronal apoptosis and degeneration in experimental intracerebral hemorrhage in rats
}

\author{
LINQIANG ZHOU ${ }^{1,2^{*}}$, CHENGLIN LIU $^{1 *}$, ZHONG WANG $^{1 *}$, HAITAO SHEN $^{1}$, \\ ZUNJIA WEN ${ }^{1}$, DONGDONG CHEN ${ }^{1}$, QING SUN ${ }^{1}$ and GANG CHEN ${ }^{1}$ \\ ${ }^{1}$ Department of Neurosurgery, The First Affiliated Hospital of Soochow University, Suzhou, Jiangsu 215006; \\ ${ }^{2}$ Department of Neurosurgery, Xiangcheng People's Hospital of Suzhou City, Suzhou, Jiangsu 215131, P.R. China
}

Received December 29, 2015; Accepted December 12, 2016

DOI: $10.3892 / \mathrm{mmr} .2018 .8624$

\begin{abstract}
Pannexins serve an important role in the regulation of extracellular neuronal regenerative currents and cellular signal transduction of glial cells; however, the effects of pannexins in various cerebrovascular diseases have not been reported. The present study focused on the expression and influence of pannexins in a rat model of intracerebral hemorrhage (ICH), and confirmed that pannexins (including Pannexin-1, Pannexin-2 and Pannexin-3) are expressed in rat brain tissues. However, only the expression of Pannexin-1 was significantly increased and peaked $48 \mathrm{~h}$ post-ICH. Following treatment with carbenoxolone (CBX), which is an inhibitor of Pannexin-1, apoptosis and neuronal degeneration in the brain tissues around the ICH hematoma decreased. The extent of secondary brain injury due to ICH was also alleviated. Compared with rats in the ICH-only group, recovery of neurocognitive functions improved significantly in the CBX-treated groups. Results from the present study suggested that the upregulation of Pannexin-1 expression may be involved in apoptosis and degeneration of neurons in the rat brain following $\mathrm{ICH}$, and may contribute to subsequent cognitive dysfunction.
\end{abstract}

\section{Introduction}

Non-traumatic intracerebral hemorrhage (ICH) is the second most common type of stroke and is associated with high mortality and high morbidity; $50-70 \%$ of survivors suffer from paralysis, aphasia and severe disability $(1,2)$. Previous studies have demonstrated that brain damage following ICH is due

Correspondence to: Dr Gang Chen or Dr Qing Sun, Department of Neurosurgery, The First Affiliated Hospital of Soochow University, 188 Shizi Street, Suzhou, Jiangsu 215006, P.R. China

E-mail: nju_neurosurgery@163.com

E-mail: qsun@suda.edu.cn

*Contributed equally

Key words: pannexin-1, intracerebral hemorrhage, carbenoxolone, apoptosis, neuronal degeneration not only to hematoma mass effect and its direct damage to the surrounding brain tissues, but also to secondary brain injury. In addition, apoptosis and degeneration of neurons post-ICH are important factors in secondary brain injury $(3,4)$. Following $\mathrm{ICH}$, there is an increase in the local concentration of glutamate, which overstimulates N-methyl-D-aspartate receptors (NMDARs) in the brain (5); this leads to an increase in intracellular $\mathrm{Ca}^{2+}$ and neuron death, suggesting that NMDARs serve an important role in neuronal apoptosis post-ICH.

Pannexins were discovered in vertebrates by Panchin et al in 2000 (6), and there are three subtypes: Pannexin-1, Pannexin-2 and Pannexin-3. Pannexins exhibit sequence homology to the invertebrate family of gap junction proteins called innexins (6). Pannexin-1 is a non-selective ion channel that is widely distributed in various tissues and is involved in several important physiological and pathophysiological functions. Pannexin-l may be part of the postsynaptic channel complex and may regulate postsynaptic activity through the formation of hemichannels (7). Pannexin-l directly mediates the release of ATP, adjusts the extracellular regenerative currents in neurons, and serves an important role in signal transduction in glial cells $(8,9)$. Furthermore, Pannexin-1 channels can be activated by ischemia, as indicated by a previous report that demonstrated that during ischemic stroke, the Pannexin-1 hemichannel opening in neurons increases after hypoxic-ischemic stress injury (10). Another study revealed that the addition of a Pannexin-1 inhibitor to hippocampal slice cultures significantly reduced the activation of caspase- 3 and neuronal cell death (11). In addition, Pannexin-1 channels have been revealed to be activated by NMDARs $(12,13)$, which further suggests an important role for Pannexin-1 in neuronal apoptosis following ICH. However, little is currently known regarding the role of Pannexin-1 post-ICH. The present study aimed to explore the expression and the role of Pannexin-1 post-ICH, which, to the best of our knowledge, has not previously been reported.

\section{Materials and methods}

Animals and ethics. All applicable international, national, and/or institutional guidelines for the care and use of animals were followed. Animal experimental protocols, including all use, care and operative procedures, were approved by the Institutional Animal Care and Use Committee of Soochow University 
(Suzhou, China) and complied with the 8th version of the Guide for the Care and Use of Laboratory Animals by the National Institutes of Health (2012).

Rat ICH model. A total of 146 male Sprague-Dawley rats (weight, 250-300 g) were purchased from the Animal Center of Soochow University (Suzhou, China) and were raised on a 12-h dark-light cycle with free access to food and water. They were anesthetized with an intraperitoneal injection of pentobarbital (45 mg/kg; Sigma-Aldrich; Merck Millipore, Darmstadt, Germany). Core temperature was maintained at $37^{\circ} \mathrm{C}$ using a feedback-controlled heating pad. Rats were positioned in a stereotactic frame (David Kopf Instruments, Tujunga, CA, USA) and a cranial burr hole (1 mm) was drilled on the right coronal suture, $3.5 \mathrm{~mm}$ lateral to midline. A 30-gauge needle was introduced through the burr hole into the caudate nucleus, $3.5 \mathrm{~mm}$ lateral to midline and $0.2 \mathrm{~mm}$ anterior to the bregma, and to a depth of $5.5 \mathrm{~mm}$ below the surface of the skull. A microinjector was used to infuse $1 \mu \mathrm{l}$ buffered saline containing 0.23 units type VII collagenase (Merck Millipore) over $5 \mathrm{~min}$, to break up the basement of vessels and cause internal bleeding. The needle was kept in place for an additional 5 min post-injection to avoid reflux. Sham controls only had an intracerebral needle insertion. Following injection, the needle was removed, the burr hole was filled with bone wax and the skin incision was closed with sutures $(14,15)$. Animals were then re-anesthetized as above and perfused for $5 \mathrm{~min}$ through the left cardiac ventricle with $0.9 \% \mathrm{NaCl}$ solution, until effluent from the right atrium was clear, the brain was removed and a coronal tissue slice $(3 \mathrm{~mm}$ ) was cut $4 \mathrm{~mm}$ from the frontal pole. Two tissue samples, the ipsilateral and the contralateral cortex, were obtained from each brain.

Experimental design. In experiment 1 (Fig. 1A), 42 of the 54 rats survived and were assigned randomly into 7 groups (n=6/group): 1 sham group (control) and 6 post-ICH groups $(6$, 12, 24, 48 and $72 \mathrm{~h}$, and 7 days). The animals in the post-ICH groups were subjected to experimental induction of $\mathrm{ICH}$ on day 0 and were sacrificed via the aforementioned procedure, after $6,12,24,48,72 \mathrm{~h}$ and 7 days, respectively.

In experiment 2 (Fig. 1B), 72 of the 92 rats survived and were assigned randomly into 4 groups (n=18/group): Sham group; ICH group; ICH + low concentration carbenoxolone (CBX-L; cat. no. A8389; $10 \mathrm{mg} / \mathrm{kg}$; ApexBio Technology, Houstoun, TX, USA) group; and ICH + high concentration CBX (CBX-H; $20 \mathrm{mg} / \mathrm{kg}$ ) group. The concentration of CBX treatment used was according to a previous study (16). A CBX stock solution was diluted to $50 \mathrm{mg} / \mathrm{ml}$ in sterile saline; the required concentration for each group was then prepared prior to intraperitoneal injection, which occurred $1 \mathrm{~h}$ post-ICH induction. A total of 6 rats were selected randomly from each group and sacrificed using the aforementioned procedure, $48 \mathrm{~h}$ post- $\mathrm{ICH}$. An additional 6 rats were used to evaluate brain edema and the remaining rats underwent nerve function score tests $48 \mathrm{~h}$ following $\mathrm{ICH}$.

Western blot analysis. Brain tissue samples from the ipsilateral and contralateral cortex were mechanically lysed in lysis buffer containing $20 \mathrm{mmol}$ Tris (pH 7.6), 0.2\% SDS, $1 \%$ Triton X-100, 1\% deoxycholate, $1 \mathrm{mmol}$ phenylmethylsulfonyl fluoride and $0.11 \mathrm{U} / \mathrm{ml}$ aprotinin (Merck Millipore). The lysates were centrifuged at $12,000 \mathrm{x}$ g for $20 \mathrm{~min}$ at $4^{\circ} \mathrm{C}$, and the protein concentration was estimated using the Bradford method. Samples $(60 \mu \mathrm{g})$ were separated by $10 \%$ SDS-PAGE and electrotransferred onto a nitrocellulose membrane (Merck Millipore). The membranes were blocked with 5\% non-fat milk for $1 \mathrm{~h}$ at room temperature and then incubated with primary antibodies against Pannexin-1 (cat. no. ab124131; Abcam, Cambridge, MA, USA), Pannexin-2 (cat. no. sc-51384; Santa Cruz Biotechnology, Inc., Dallas, TX, USA), Pannexin-3 (cat. no. ab98093; Abcam), active-caspase-3 (cat. no. ab2302; Abcam) or albumin (cat. no. ab207327; Abcam) at dilutions of 1:500 in 5\% bovine serum albumin (BSA; Beyotime Institute of Biotechnology, Haimen, China) in TBS $+0.1 \%$ Tween-20 overnight at $4^{\circ} \mathrm{C}$. GAPDH (1:6,000; Merck Millipore) was used as a loading control. The membranes were washed 3 times for 5 min each in TBS $+0.1 \%$ Tween- 20 and then incubated with the appropriate horseradish peroxidase-conjugated secondary antibodies (cat. no. SC-2004; 1:5,000 in 5\% BSA; Santa Cruz Biotechnology, Inc.) for $2 \mathrm{~h}$ at room temperature. Finally, protein bands were visualized using enhanced chemiluminescence (ECL; Thermo Fisher Scientific, Inc., Waltham, MA, USA) and were exposed to X-ray film. Relative changes in protein expression were estimated from the mean pixel density using UN-SCAN-IT, normalized to $\beta$-actin, and calculated as target protein expression $/ \beta$-actin expression ratios.

Immunofluorescence microscopy. Following collection, brain tissue samples from the ipsilateral cortex were embedded in Tissue-Tek Optimal Cutting Temperature Embedding Compound (Sakura Finetek Japan Co., Ltd., Tokyo, Japan). Sections $4 \mu \mathrm{m}$ thick were sliced and blocked with $5 \%$ normal fetal bovine serum in PBS containing $0.1 \%$ Triton X-100 for $2 \mathrm{~h}$ at room temperature. Following this, sections $(4 \mu \mathrm{m})$ were then incubated with primary antibodies against Pannexin-1, Pannexin-2 or Pannexin-3 and Neuronal nuclei (NeuN; cat. no. ab104224; Abcam) overnight at $4^{\circ} \mathrm{C}$. Following this, sections were washed three times with PBS for $45 \mathrm{~min}$ and were immunolabeled with the appropriate secondary antibodies (Alexa Fluor 488, cat. no. A21206 and Alexa Fluor 555, cat. no. A31570; 1:200; Invitrogen, Thermo Fisher Scientific, Inc.) for $1 \mathrm{~h}$ at room temperature. The slides were washed with PBS again three times for $45 \mathrm{~min}$ prior to counterstaining with DAPI to stain the nuclei, for $2 \mathrm{~min}$. A total of 3 random sections from each rat were examined and imaged using a fluorescence microscope (Olympus Corporation, Tokyo, Japan). Relative fluorescence intensity was analyzed using ImageJ software version 2 (National Institutes of Health, Bethesda, MA, USA).

Neurobehavioral testing and neurological scoring. Three behavioral activity examinations were performed $48 \mathrm{~h}$ post-ICH on 24 rats that were separated into 4 groups (n=6/group: Sham; $\mathrm{ICH}$; ICH + CBX-L; and ICH + CBX-H), to record appetite, activity and neurological deficits using the scoring system reported previously (17). The standard of behavior and activity scores are shown in Table I.

Brain edema and blood-brain barrier $(B B B)$ integrity. Brain water content was evaluated using the wet/dry weight method as previously described (18), and BBB integrity was measured by evaluating albumin levels in the ipsilateral cortex, detected 
A

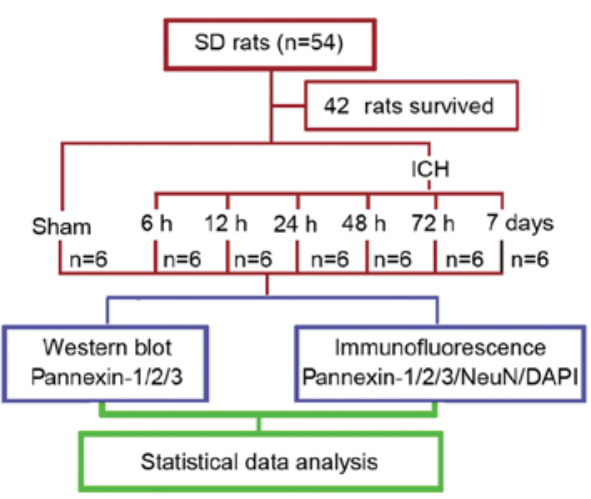

B

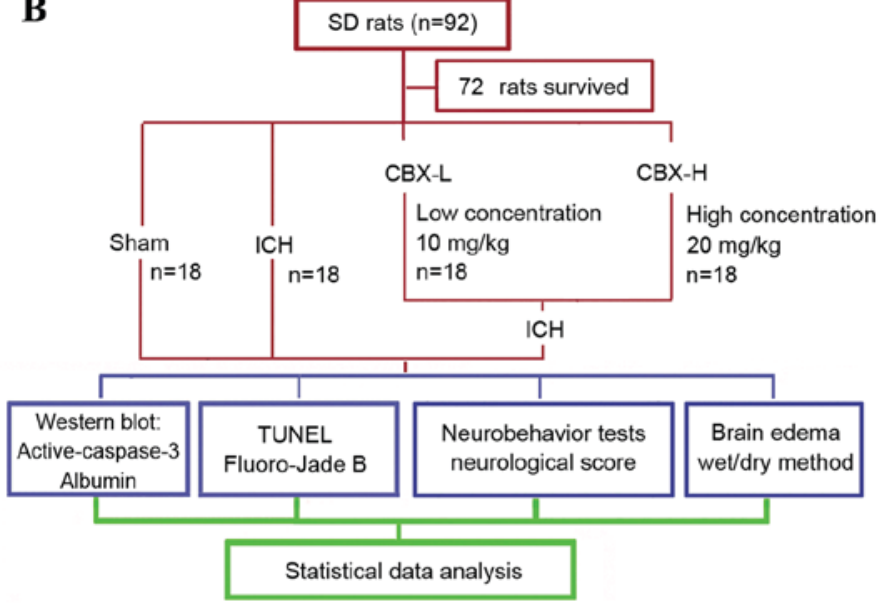

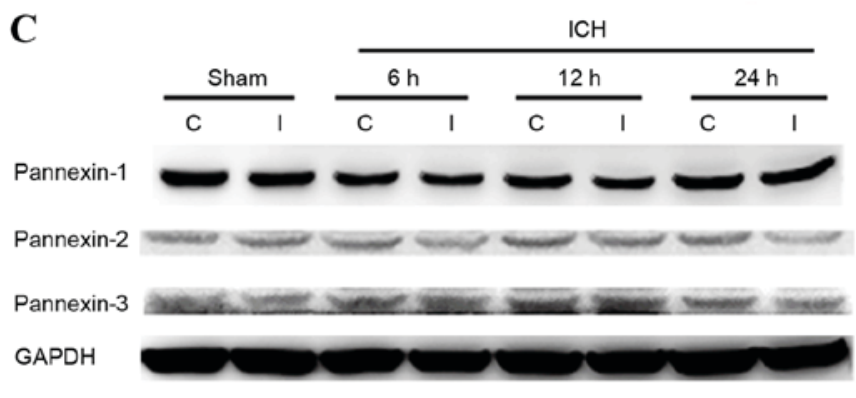

D

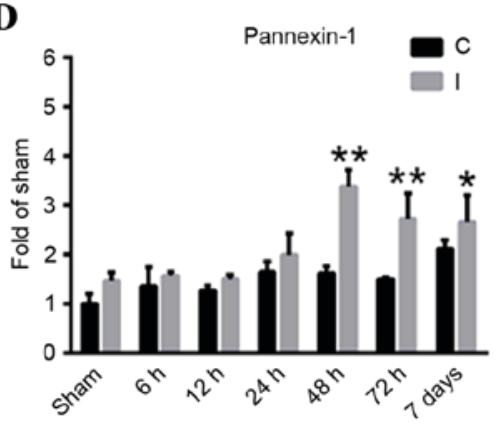

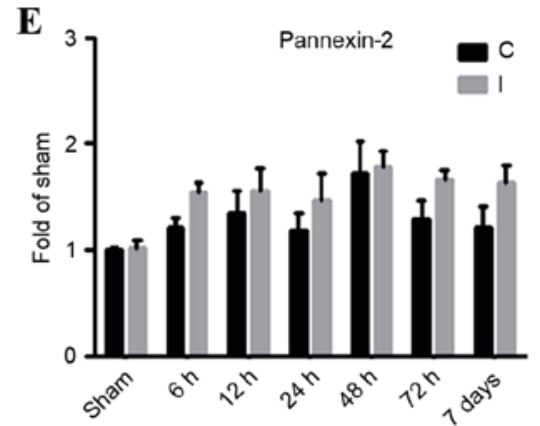

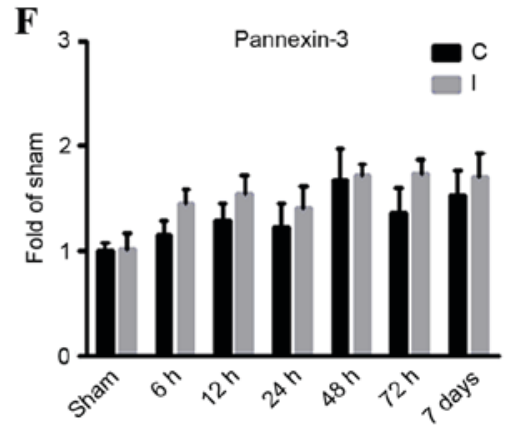

Figure 1. Experimental designs and time course of pannexin protein expression detection in rat brain tissues following ICH. (A) Experiment 1 was designed to detect changes in the levels of protein expression of Pannexin-1, Pannexin-2 and Pannexin-3 in the brain tissues of rats following ICH. (B) Experiment 2 was designed to investigate the role of Pannexin-1 in neuronal apoptosis and degeneration in rats post-ICH. (C) Western blot analyses and quantitative analyses of the relative protein expression levels of (D) Pannexin-1, (E) Pannexin-2 and (F) Pannexin-3 in brain tissues post-ICH; the mean band intensity of the sham group was normalized to 1.0. Data are presented as the mean \pm standard error of the mean; ${ }^{*} \mathrm{P}<0.05,{ }^{* *} \mathrm{P}<0.01$ vs. sham group; $\mathrm{n}=6 /$ group. $\mathrm{C}$, contralateral; CBX, carbenoxolone; I, ipsilateral; ICH, intracerebral hemorrhage; NeuN, Neuronal nuclei; SD, Sprague-Dawley; TUNEL, terminal deoxynucleotidlyltransferase-mediated dUTP nick end labeling.

via western blotting. To assess brain water content, 24 rats were separated into 4 groups (n=6/group): Sham; ICH; $\mathrm{ICH}+\mathrm{CBX}-\mathrm{L}$; and ICH + CBX-H. Rats were anesthetized with an intraperitoneal injection of $45 \mathrm{mg} / \mathrm{kg}$ pentobarbital and decapitated $48 \mathrm{~h}$ post-ICH. Brains were removed, the olfactory bulbs, cerebella and brain stems were discarded, and the contralateral and ipsilateral hemispheres were separated. Each sample was weighed to obtain the wet weight and then dried in an oven at $100^{\circ} \mathrm{C}$ for $24 \mathrm{~h}$ to obtain the dry weight. Water content was expressed as a percentage of the wet weight: (wet weight - dry weight)/wet weight $\mathrm{x} 100 \%$.

Terminal deoxynucleotidlyl-transferase-mediated dUTP nick end labeling (TUNEL)/NeuN immunofluorescence double labeling. As described previously (18), cell apoptosis in brain tissues was detected by TUNEL staining using the In Situ Cell Death Detection kit (Roche Diagnostics, Indianapolis, IN, USA), according to the manufacturer's protocol. To further identify neuronal apoptosis in the brain, TUNEL-stained slides were incubated with anti-NeuN primary antibody (cat. no. ab104224, 1:200; Abcam) overnight, and then incubated with secondary donkey anti-mouse immunoglobulin G (Alexa Fluor 555; cat. no. A31570; 1:200; Molecular Probes; Thermo Fisher Scientific, Inc.) at room temperature, visualized by a fluorescence microscope (Olympus Corporation). A total of 3 sections per rat were examined and imaged in parallel for counting TUNEL-positive cells.

Fluoro-Jade B staining. Frozen brain (the ipsilateral cortex) sections were stained with Fluoro-Jade B as previously 
Table I. Behavior and activity scores.

\begin{tabular}{llc}
\hline Category & \multicolumn{1}{c}{ Behavior } & Score \\
\hline Appetite & Finished meal & 0 \\
& Left meal unfinished & 1 \\
& Scarcely ate & 2 \\
Activity & Walked and reached at least three & 0 \\
& corners of the cage & \\
& Walked with some stimulations & 2 \\
& Almost always lying down & 0 \\
Deficits & No deficits & 1 \\
& Unstable walk & 2 \\
& Impossible to walk &
\end{tabular}

Table II. Clinical behavior scores in each group.

\begin{tabular}{lc}
\hline Group & Mean score \\
\hline Sham (n=18) & 0.61 \\
ICH (n=18) & $3.01^{\mathrm{a}}$ \\
ICH + CBX (low, $\mathrm{n}=18)$ & $2.11^{\mathrm{b}}$ \\
ICH + CBX (high, $\mathrm{n}=18)$ & $1.87^{\mathrm{c}}$ \\
\hline
\end{tabular}

${ }^{\mathrm{a}} \mathrm{P}<0.01$ vs. sham group; ${ }^{\mathrm{b}} \mathrm{P}<0.05,{ }^{\mathrm{c}} \mathrm{P}<0.01$ vs. $\mathrm{ICH}$ group.

described (19). Briefly, brain sections were incubated in $100 \%$ ethanol for $3 \mathrm{~min}, 70 \%$ ethanol for $1 \mathrm{~min}$ and then washed with deionized water. Sections were incubated for $10 \mathrm{~min}$ in $0.06 \%$ potassium permanganate followed by $60 \mathrm{~min}$ in Fluoro-Jade B solution (Histo-Chem, Inc., Jefferson, AR, USA). Subsequently, the sections were washed 3 times with PBS and dried overnight at room temperature. Following drying, samples were cleared with xylene, a coverslip was added using DPX Mountant (Electron Microscopy Sciences, Hatfield, PA, USA) and visualized using a fluorescence microscope (Olympus Corporation). A total of 3 sections per rat were examined and imaged in parallel for counting Fluoro-Jade B-positive cells using ImageJ software, version 2 (National Institutes of Health).

Statistical analysis. All data are presented as the mean \pm standard error of the mean. GraphPad Prism 5 software (GraphPad Software, Inc., La Jolla, CA, USA) was used for all statistical analysis. All data were analyzed using one-way analysis of variance. The significance of differences among experimental groups was determined by Fisher's least significant difference post-test and $\mathrm{P}<0.05$ was considered to indicate a statistically significant difference.

\section{Results}

Expression of pannexin proteins in rat brain tissues at various time points following ICH. Pannexin-1 was expressed in the ipsilateral and contralateral cortices in the sham and $\mathrm{ICH}$ groups at each of the six time points (Fig. 1C and D). However, compared with the sham group, the expression levels of Pannexin-1 were significantly higher at 48 and $72 \mathrm{~h}(\mathrm{P}<0.01)$, as well as at 7 days $(\mathrm{P}<0.05)$ following $\mathrm{ICH}$; the expression of Pannexin-1 peaked at $48 \mathrm{~h}$ post-ICH. Although Pannexin-2 and Pannexin-3 were also expressed in $\mathrm{ICH}$ groups at each time point and in the sham group (Fig. 1C), there was no significant difference between the two groups ( $\mathrm{P}>0.05$; Fig. $1 \mathrm{E}$ and $\mathrm{F}$ ). Immunofluorescence analysis confirmed that the expression of Pannexin-1 protein in the rat brain neurons gradually increased over time and peaked $48 \mathrm{~h}$ post-ICH (Fig. 2). Conversely, the expression levels of Pannexin-2 and Pannexin-3 at each time point revealed no significant differences between ICH and sham groups (Fig. 1C-F).

CBX treatment improves cognitive function in rats post-ICH. Following $\mathrm{ICH}$, rats treated with $\mathrm{CBX}$ demonstrated significantly improved activity and appetite compared with the ICH-only group. The total combined score of the ICH-only group was significantly higher than that of sham group $(\mathrm{P}<0.01)$. However, neurological scores of the CBX-L and CBX-H treatment groups were markedly lower than the ICH group $(\mathrm{P}<0.05$ and $\mathrm{P}<0.01$, respectively). As shown in Table II, the mean neurological scores were 0.61 (sham group), 3.01 (ICH-only group), 2.11 ( $\mathrm{CH}+\mathrm{CBX}-\mathrm{L}$ group) and 1.87 ( $\mathrm{ICH}+\mathrm{CBX}-\mathrm{H}$ group).

CBX treatment reduces brain edema and BBB injury post-ICH. Brain water content was calculated using the wet/dry weight method. Compared with the sham group, the brain water content was significantly higher in the ICH-only group $(\mathrm{P}<0.05$; Fig. $3 \mathrm{~A})$. However, brain water content of the ICH + CBX-L and $\mathrm{ICH}+$ $\mathrm{CBX}-\mathrm{H}$ groups was lower than in the $\mathrm{ICH}$-only group $(\mathrm{P}<0.05$ and $\mathrm{P}<0.01$, respectively; Fig. 3A). To evaluate the effects of $\mathrm{CBX}$ treatment on $\mathrm{BBB}$ integrity following $\mathrm{ICH}$, the protein expression levels of albumin were detected by western blot analysis (Fig. 3B). The results suggested that CBX treatment could reduce the leakage of albumin content in brain tissue which indicated that $\mathrm{CBX}$ treatment may attenuate BBB injury after ICH (Fig. 3B and C). In addition, CBX treatment also reduced $\mathrm{ICH}$-induced increase in the level of active-caspase3, which indicated that $\mathrm{CBX}$ treatment may attenuate brain cell apoptosis following ICH (Fig. 3B and D).

CBX treatment inhibits neuronal apoptosis and neuronal degeneration in rat brain tissues following ICH. Neuronal apoptosis was detected by TUNEL staining in each of the four treatment groups. The results indicated that the rate of apoptosis in neurons was significantly higher in the ICH-only group compared with the sham group $(\mathrm{P}<0.01)$, whereas the number of apoptotic neurons in the CBX-L and CBX-H treatment groups was significantly lower than in the ICH-only group ( $\mathrm{P}<0.05$ and $\mathrm{P}<0.01$, respectively; Fig. $4 \mathrm{~A}$ and $\mathrm{B})$. Results of Fluoro-Jade $\mathrm{B}$ assay revealed that the rate of neuronal degeneration was markedly increased in the $\mathrm{ICH}$-only group compared with the sham group $(\mathrm{P}<0.01)$. However, the rates of neuronal degeneration in the $\mathrm{CBX}-\mathrm{L}$ or $\mathrm{CBX}-\mathrm{H}$ groups were significantly lower than that in the ICH-only group $(\mathrm{P}<0.05$ and $\mathrm{P}<0.01$, respectively; Fig. 4C and D). Western blot analysis confirmed that the expression levels of active-caspase-3 protein were significantly higher in the ICH-only group compared with the sham group $(\mathrm{P}<0.05$; Fig. $3 \mathrm{~B}$ and $\mathrm{D})$. However, the 
A

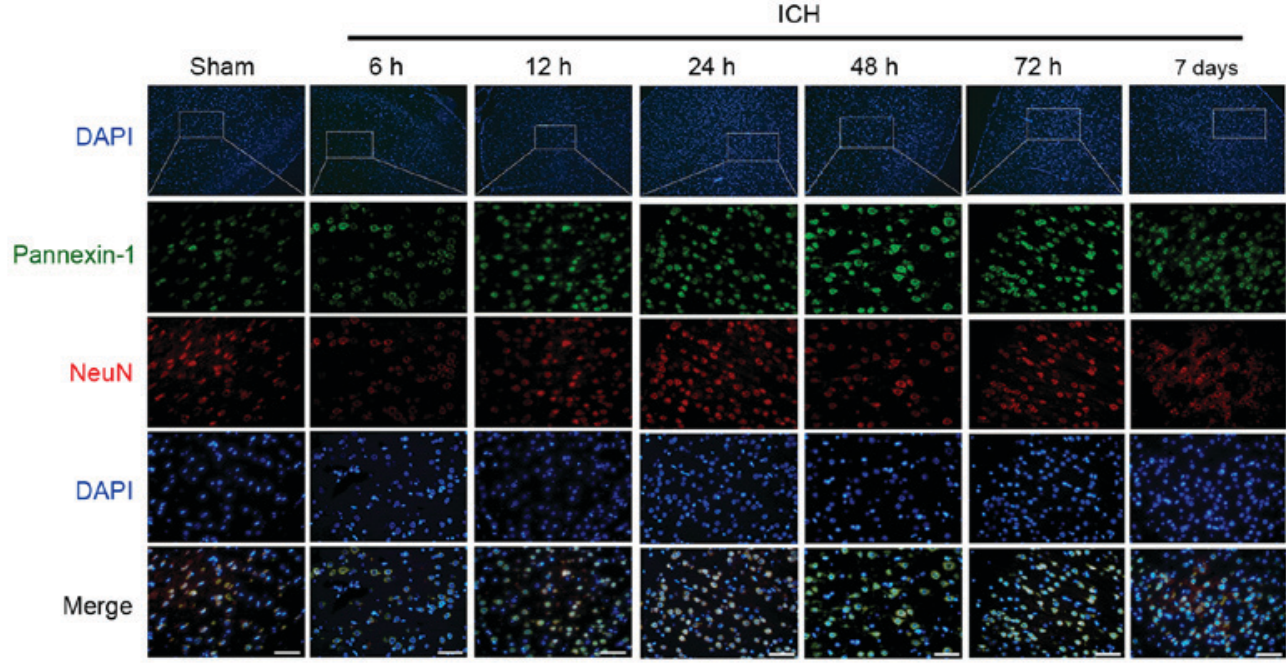

B

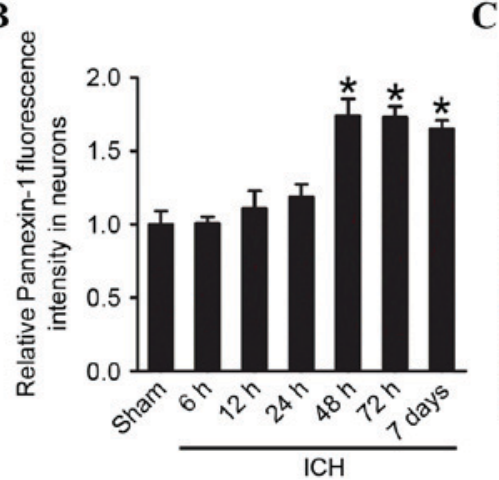

C

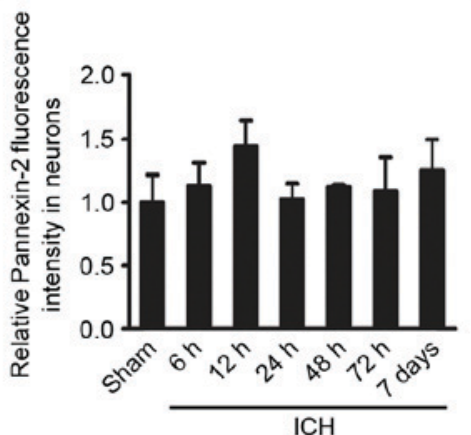

D

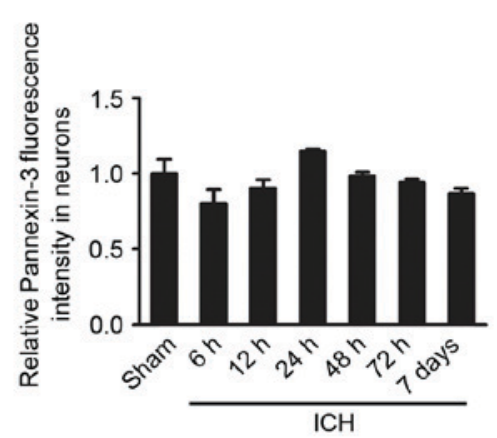

Figure 2. Time course of pannexin protein expression in the rat brain tissues following ICH. (A) Immunofluorescence microscopy revealing the expression of Pannexin-1 over time. Cells were counterstained with NeuN (a neuronal marker) and DAPI (a nuclear marker). Quantification of the relative fluorescence intensity of (B) Pannexin-1, (C) Pannexin-2 and (D) Pannexin-3. The mean fluorescence intensity of the sham group was normalized to 1.0. Scale bar, $60 \mu \mathrm{m}$. Data are presented as the mean \pm standard error of the mean. ${ }^{*} \mathrm{P}<0.05$ vs. sham group; $\mathrm{n}=10$. ICH, intracerebral hemorrhage; NeuN, Neuronal nuclei.

A

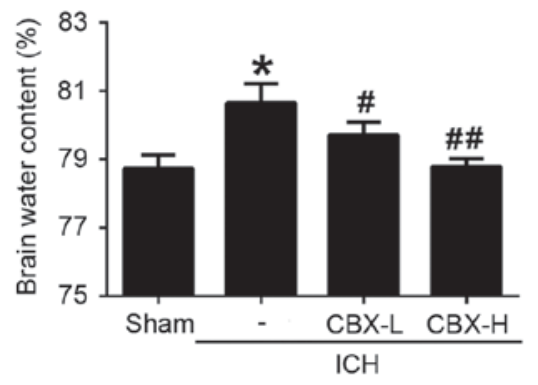

C

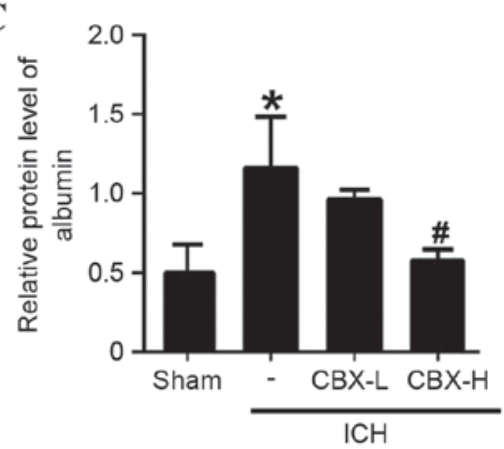

B

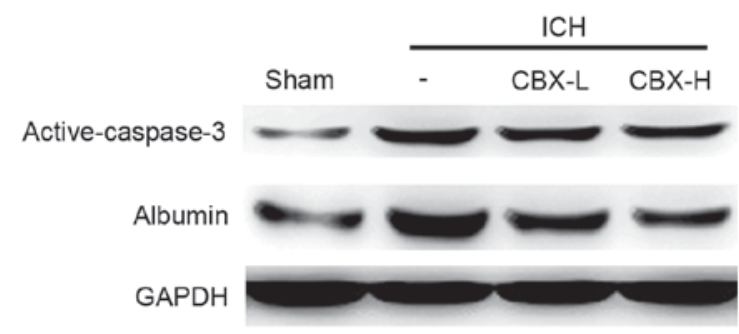

D

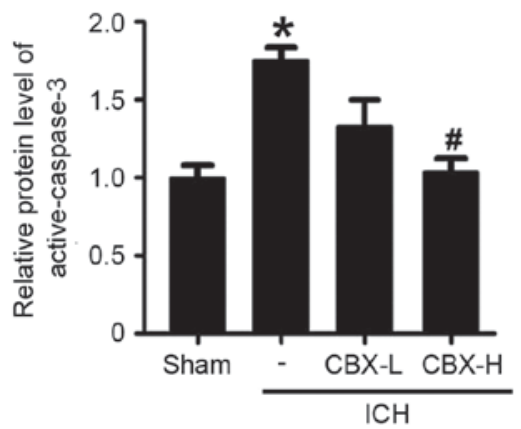

Figure 3. Effects of CBX treatment on brain edema, integrity and active-caspase-3 level following ICH. (A) Brain water content was measured by the wet/dry weight method at $48 \mathrm{~h}$ post-ICH. (B) The effects of $\mathrm{CBX}$ treatment on BBB integrity and neuronal apoptosis post-ICH were detected by the protein expression levels of albumin and active-caspase-3. Quantitative analyses of the relative protein levels of (C) albumin and (D) active-caspase-3. The mean band intensity of the sham group was normalized to 1.0. Data are presented as the mean \pm standard error of the mean. ${ }^{*} \mathrm{P}<0.05$ vs. sham group; ${ }^{\#} \mathrm{P}<0.05$ vs. ICH group; ${ }^{\# \#} \mathrm{P}<0.01$ vs. ICH group; n=6/group. BBB, blood-brain barrier; CBX, carbenoxolone; H, high; ICH, intracerebral hemorrhage; L, low. 
$\mathbf{A}$

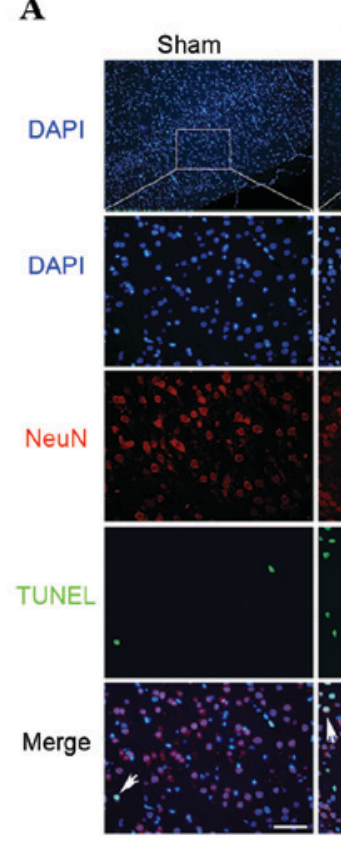

C
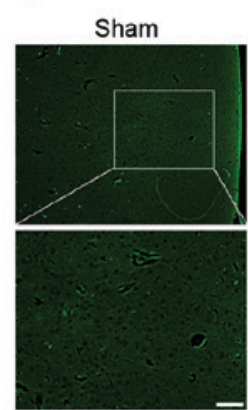

$\mathrm{ICH}$
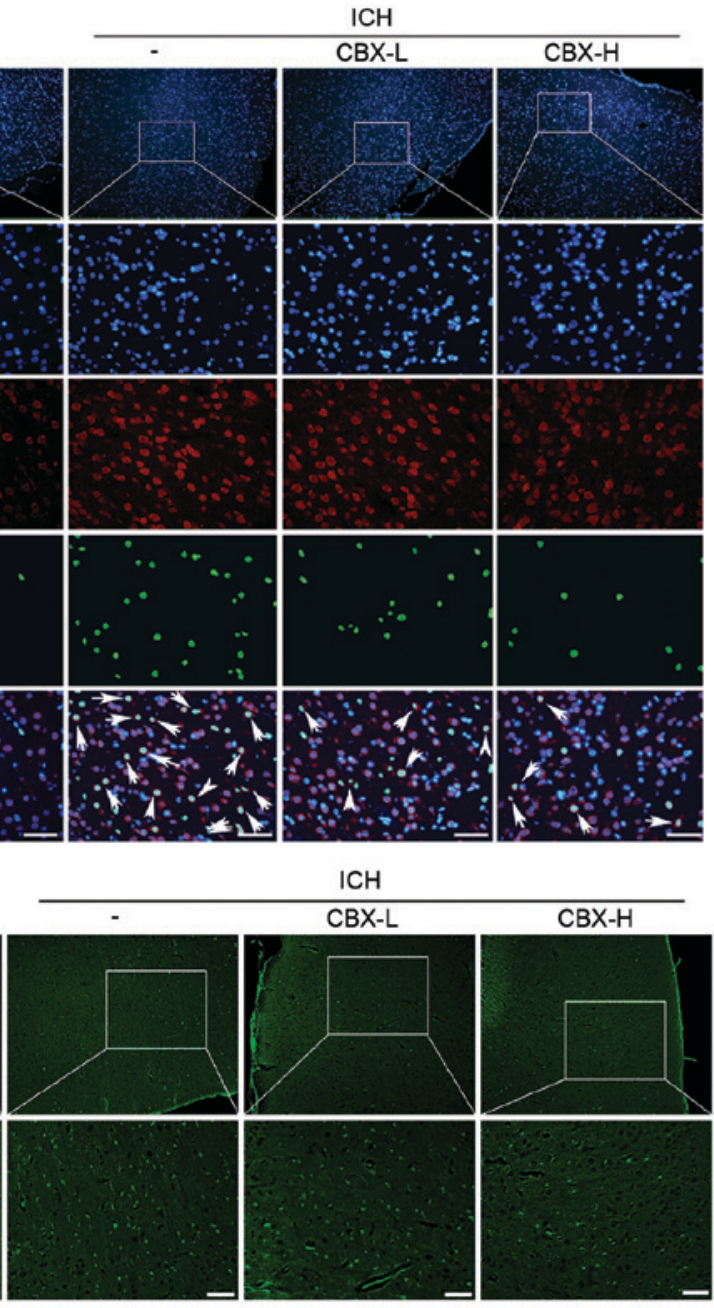

$\mathrm{ICH}$
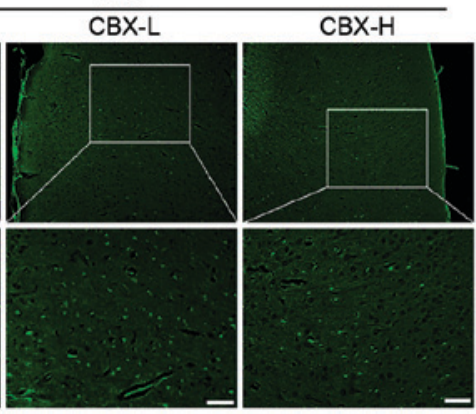

B
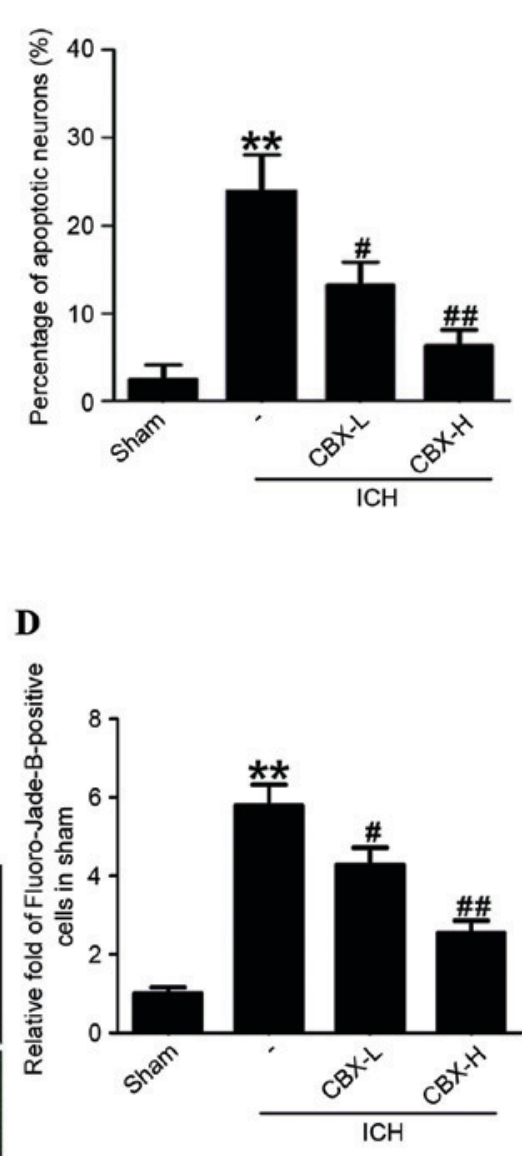

Figure 4. CBX treatment of ICH rats decreased neuronal apoptosis and degeneration in brain tissues. (A) Apoptotic cells were detected by TUNEL staining (arrows in merged image), neurons were counterstained with NeuN (neuronal marker) and DAPI (nuclear marker). (B) Percentage of TUNEL-positive neurons in each group. (C) Neuronal degeneration was detected by Fluoro-Jade B staining. (D) Quantification of Fluoro-Jade B-positive cells. The mean number of Fluoro-Jade B-positive cells in the sham group was normalized to 1.0. Scale bar, $60 \mu \mathrm{m}$. Data are presented as the mean \pm standard error of the mean. ${ }^{* *} \mathrm{P}<0.01$ vs. sham group; $\mathrm{P}<0.05$ vs. ICH group; ${ }^{\# \#} \mathrm{P}<0.01$ vs. ICH group; $\mathrm{n}=10$. CBX, carbenoxolone; H, high; ICH, intracerebral hemorrhage; L, low; NeuN, Neuronal nuclei; TUNEL, terminal deoxynucleotidlyl-transferase-mediated dUTP nick end labeling.

expression levels of active-caspase-3 were significantly lower in the $\mathrm{ICH}+\mathrm{CBX}-\mathrm{H}$ treatment group compared with the ICH-only group $(\mathrm{P}<0.05)$. There was no significant difference in the expression of active-caspase- 3 between the CBX-L treatment group and the ICH-only group ( $\mathrm{P}>0.05$; Fig. 3B and $\mathrm{D})$.

\section{Discussion}

Pannexin-1 is a member of the vertebrate pannexin family of gap junction proteins, which was identified after the connexins and exhibits sequence homology with the invertebrate innexins (6). Pannexin-1 is able to form functional gap junctions when expressed in paired Xenopus oocytes, and forms unconjugated hemichannels in cultured neurons and glial cells. The hemichannels are typically closed under resting conditions and permit $\mathrm{Ca}^{2+}$ and ATP flux when they are open (7). Numerous studies have reported that the pannexins may form hemichannels in the cell membrane and mediate the release of ATP, the transmission of intercellular $\mathrm{Ca}^{2+}$ waves, the regulation of blood flow, immune responses and other physiological functions $(8,20)$. Pannexins are also involved in inflammation, cancer, cerebral ischemia, epilepsy and other pathologies $(8,20,21)$.

$\mathrm{ICH}$ is a devastating disease that is associated with high mortality, and there are no effective treatments to reduce mortality and to improve the outcome for survivors (22). Nerve injury after ICH is complex. Initial damage is due to the mechanical force induced by formation of the hematoma. Subsequent hematoma expansion, edema and inflammation cause further damage to brain tissues (23). Excitatory amino acid toxicity is a major factor in secondary brain injury following $\mathrm{ICH}$, and glutamate is the primary excitatory neurotransmitter (24). Following ICH, high concentrations of glutamate cause excessive activation of NMDARs, which leads to a large increase in $\mathrm{Ca}^{2+}$ influx, thus triggering a series of neurotoxic cascades $(25,26)$. Animal experiments have revealed that the glutamate concentration sharply increases in tissues surrounding a hematoma within $3 \mathrm{~h}$ following $\mathrm{ICH}$ and peaks at $12 \mathrm{~h}$ post-ICH (25). However, as the volume of the hematoma decreased due to absorption $48-72 \mathrm{~h}$ post-ICH, the glutamate concentration also significantly decreased, although it remained higher than the sham group. 
Pannexin-1 is one of the primary downstream proteins of NMDAR. A previous study revealed that, following repeated or prolonged stimulation, postsynaptic NMDARs induced a secondary inward current (9). A Pannexin-1 specific inhibitory peptide was able to block the inward current, indicating that NMDARs can activate Pannexin-1 hemichannels. Pannexin-1 hemichannels open in response to depolarization, hypoxia and mechanical stress. When open, they permit a large efflux of ATP, which can bind to the P2Y subclass of purinergic receptors present on vascular endothelial cells and red blood cells. The binding of ATP leads to the release of more ATP, diffusion of intracellular $\mathrm{Ca}^{2+}$ and the release of nitric oxide directly into the vascular smooth muscle cells, which promotes vasodilation and increases blood flow (27). The present study demonstrated that the expression of Pannexin-1 increased over time following $\mathrm{ICH}$, peaking at $48 \mathrm{~h}$ post- $\mathrm{ICH}$; the delay in expression relative to the peak time point of increased glutamate concentration ( $12 \mathrm{~h}$ post-ICH) is probably because Pannexin-1 is downstream of NMDAR signaling.

CBX is a traditional anti-ulcer drug, but it also exhibits anti-inflammatory effects by stimulating the adrenal glands or enhancing endogenous corticosteroids (28). CBX is a broad-spectrum gap junction inhibitor that permeates the BBB (29). CBX binds directly to gap junction channels, which results in a conformational change in the gap junction and the closing of hemichannels (30). A previous study revealed that CBX effectively reduces the depolarization-induced pannexin hemichannel current in Xenopus oocyte assays, and the effect was concentration-dependent (20). Another study compared the effects of compounds known to inhibit cation and anion channels, and demonstrated that CBX was the most effective inhibitor of Pannexin-1 hemichannels in mammalian cell lines (31). The suppressive effect of CBX was rapid and readily reversible. These results suggested that CBX may act directly on Pannexin-1 hemichannels. To confirm this finding, further studies are necessary in the future.

Inhibition of gap junctions may serve a neuroprotective role, which has been demonstrated in several in vitro and in vivo models of nerve injury. One study demonstrated that CBX significantly reduced the activation of caspase- 3 and decreased neuronal death in hippocampal slice cultures after oxygen-glucose deprivation for $60 \mathrm{~min}$ (11). Using an intrauterine hypoxic-ischemic model, it was revealed that treatment with CBX significantly reduced newborn cub mortality and improved long-term developmental defects (11). However, there have been almost no studies on the effects of gap junction inhibitors on secondary brain injury following ICH. One study demonstrated that intravenous and intraperitoneal injections of CBX significantly reduced seizure severity in rats that were genetically susceptible to epilepsy; the effect was dose-dependent within the range of $5-30 \mathrm{mg} / \mathrm{kg} \mathrm{CBX} \mathrm{(16).}$ Therefore, CBX may effectively provide neuroprotection and merits further study. The present study, to the best of our knowledge, is the first to investigate the effect of gap junction inhibition on secondary brain injury, and suggested that inhibition of Pannexin-1 may be a target for the treatment of ICH.

In conclusion, the present study confirmed that Pannexin-1 expression was increased following ICH. Furthermore, the elevated expression of Pannexin-1 served an important role in cognitive dysfunction post-ICH. In addition, CBX inhibition of
Pannexin-1 effectively reduced ICH-induced brain edema and improved cognitive function. CBX also significantly reduced the expression levels of active-caspase- 3 and decreased neuronal apoptosis and degeneration. Results of the present study indicated that CBX may have a protective role in brain damage following $\mathrm{ICH}$.

\section{Acknowledgements}

The present study was supported by the National Natural Science Foundation of China (grant nos. 81371279, 81422013 and 81471196), Jiangsu Province's Outstanding Medical Academic Leader program (grant no. LJ201139), the Scientific Department of Jiangsu Province (grant no. BL2014045), the Suzhou Government (grant nos. LCZX201301, SZS201413 and SYS201332), and A Project Funded by the Priority Academic Program Development of Jiangsu Higher Education Institutions.

\section{Competing interests}

The authors declare that they have no competing interests.

\section{References}

1. Broderick JP, Brott T, Tomsick T, Miller R and Huster G: Intracerebral hemorrhage more than twice as common as subarachnoid hemorrhage. J Neurosurg 78: 188-191, 1993.

2. Zhang LF, Yang J, Hong Z, Yuan GG, Zhou BF, Zhao LC, Huang YN, Chen J and Wu YF; Collaborative Group of China Multicenter Study of Cardiovascular Epidemiology: Proportion of different subtypes of stroke in China. Stroke 34: 2091-2096, 2003.

3. Qureshi AI,Ling GS, Khan J, Suri MF, Miskolczi L, Guterman LR and Hopkins LN: Quantitative analysis of injured, necrotic and apoptotic cells in a new experimental model of intracerebral hemorrhage. Crit Care Med 29: 152-157, 2001.

4. Rincon F and Mayer SA: Novel therapies for intracerebral hemorrhage. Curr Opin Crit Care 10: 94-100, 2004.

5. Hossain MI, Kamaruddin MA and Cheng HC: Aberrant regulation and function of Src family tyrosine kinases: Their potential contributions to glutamate-induced neurotoxicity. Clin Exp Pharmacol Physiol 39: 684-691, 2012.

6. Panchin Y, Kelmanson I, Matz M, Lukyanov K, Usman N and Lukyanov S: A ubiquitous family of putative gap junction molecules. Curr Biol 10: R473-R474, 2000.

7. Zoidl G, Petrasch-Parwez E, Ray A, Meier C, Bunse S, Habbes HW, Dahl G and Dermietzel R: Localization of the pannexin 1 protein at postsynaptic sites in the cerebral cortex and hippocampus. Neuroscience 146: 9-16, 2007.

8. Iglesias R, Dahl G, Qiu F, Spray DC and Scemes E: Pannexin 1: The molecular substrate of astrocyte 'hemichannels' J Neurosci 29: 7092-7097, 2009.

9. Thompson RJ, Jackson MF, Olah ME, Rungta RL, Hines DJ, Beazely MA, MacDonald JF and MacVicar BA: Activation of pannexin-1 hemichannels augments aberrant bursting in the hippocampus. Science 322: 1555-1559, 2008.

10. Zhang L, Deng T, Sun Y, Liu K, Yang Y and Zheng X: Role for nitric oxide in permeability of hippocampal neuronal hemichannels during oxygen glucose deprivation. J Neurosci Res 86: 2281-2291, 2008.

11. de Pina-Benabou MH, Szostak V, Kyrozis A, Rempe D, Uziel D, Urban-Maldonado M, Benabou S, Spray DC, Federoff HJ, Stanton PK and Rozental R: Blockade of gap junctions in vivo provides neuroprotection after perinatal global ischemia. Stroke 36: 2232-2237, 2005.

12. Madry C, Haglerød C and Attwell D: The role of pannexin hemichannels in the anoxic depolarization of hippocampal pyramidal cells. Brain 133: 3755-3763, 2010.

13. Weilinger NL, Tang PL and Thompson RJ: Anoxia-induced NMDA receptor activation opens pannexin channels via Src family kinases. J Neurosci 32: 12579-12588, 2012. 
14. Liew HK, Pang CY, Hsu CW, Wang MJ, Li TY, Peng HF, Kuo JS and Wang JY: Systemic administration of urocortin after intracerebral hemorrhage reduces neurological deficits and neuroinflammation in rats. J Neuroinflammation 9: 13, 2012.

15. Okauchi M, Hua Y, Keep RF, Morgenstern LB, Schallert T and Xi G: Deferoxamine treatment for intracerebral hemorrhage in aged rats: Therapeutic time window and optimal duration. Stroke 41: 375-382, 2010

16. Gareri P, Condorelli D, Belluardo N, Russo E, Loiacono A Barresi V, Trovato-Salinaro A, Mirone MB, Ferreri IG and De Sarro G: Anticonvulsant effects of carbenoxolone in genetically epilepsy prone rats (GEPRs). Neuropharmacology 47: 1205-1216, 2004.

17. Chen G, Li Q, Feng D, Hu T, Fang Q and Wang Z: Expression of $\mathrm{NR} 2 \mathrm{~B}$ in different brain regions and effect of NR2B antagonism on learning deficits after experimental subarachnoid hemorrhage. Neuroscience 231: 136-144, 2013.

18. Wang Y, Gao A, Xu X, Dang B, You W, Li H, Yu Z and Chen G: The neuroprotection of lysosomotropic agents in experimental subarachnoid hemorrhage probably involving the apoptosis pathway triggering by cathepsins via chelating intralysosomal iron. Mol Neurobiol 52: 64-77, 2015.

19. Friedrich V, Flores R and Sehba FA: Cell death starts early after subarachnoid hemorrhage. Neurosci Lett 512: 6-11, 2012.

20. Bruzzone R, Hormuzdi SG, Barbe MT, Herb A and Monyer H: Pannexins, a family of gap junction proteins expressed in brain. Proc Natl Acad Sci USA 100: 13644-13649, 2003.

21. Chekeni FB, Elliott MR, Sandilos JK, Walk SF, Kinchen JM, Lazarowski ER, Armstrong AJ, Penuela S, Laird DW, Salvesen GS, et al: Pannexin 1 channels mediate 'find-me' signal release and membrane permeability during apoptosis. Nature 467: 863-867, 2010.

22. Balami JS and Buchan AM: Complications of intracerebral haemorrhage. Lancet Neurol 11: 101-118, 2012.

23. Xi G, Hua Y, Bhasin RR, Ennis SR, Keep RF and Hoff JT: Mechanisms of edema formation after intracerebral hemorrhage: Effects of extravasated red blood cells on blood flow and blood-brain barrier integrity. Stroke 32: 2932-2938, 2001 .
24. Castillo J, Dávalos A, Naveiro J and Noya M: Neuroexcitatory amino acids and their relation to infarct size and neurological deficit in ischemic stroke. Stroke 27: 1060-1065, 1996.

25. Qureshi AI, Ali Z, Suri MF, Shuaib A, Baker G, Todd K, Guterman LR and Hopkins LN: Extracellular glutamate and other amino acids in experimental intracerebral hemorrhage: An in vivo microdialysis study. Crit Care Med 31: 1482-1489, 2003.

26. Mailly F, Marin P, Israël M, Glowinski J and Prémont J: Increase in external glutamate and NMDA receptor activation contribute to $\mathrm{H}_{2} \mathrm{O}_{2}$-induced neuronal apoptosis. J Neurochem 73: 1181-1188, 1999.

27. Thompson RJ, Zhou N and MacVicar BA: Ischemia opens neuronal gap junction hemichannels. Science 312: 924-927, 2006

28. Turpie AG and Thomson TJ: Carbenoxolone sodium in the treatment of gastric ulcer with special reference to side-effects. Gut 6 591-594, 1965.

29. Traub RD, Whittington MA, Buhl EH, LeBeau FE, Bibbig A, Boyd S, Cross $\mathrm{H}$ and Baldeweg T: A possible role for gap junctions in generation of very fast EEG oscillations preceding the onset of and perhaps initiating, seizures. Epilepsia 42: 153-170, 2001.

30. Carlen PL, Skinner F, Zhang L, Naus C, Kushnir M and Perez VJ: The role of gap junctions in seizures. Brain Res Brain Res Rev 32: 235-241, 2000 .

31. Ma W, Hui H, Pelegrin P and Surprenant A: Pharmacological characterization of pannexin-1 currents expressed in mammalian cells. J Pharmacol Exp Ther 328: 409-418, 2009.

This work is licensed under a Creative Commons Attribution-NonCommercial-NoDerivatives 4.0 International (CC BY-NC-ND 4.0) License. 